\title{
Compressive loads on the lumbar spine during lifting: 4D WATBAK versus inverse dynamics calculations
}

doi:10.1533/abbi.2004.0029

\author{
M. H. Cole and P. N. Grimshaw \\ Biomechanics Laboratory, School of Health Sciences, University of South Australia, Adelaide, Australia
}

\begin{abstract}
Numerous two- and three-dimensional biomechanical models exist for the purpose of assessing the stresses placed on the lumbar spine during the performance of a manual material handling task. More recently, researchers have utilised their knowledge to develop specific computer-based models that can be applied in an occupational setting; an example of which is 4D WATBAK. The model used by 4D WATBAK bases its predications on static calculations and it is assumed that these static loads reasonably depict the actual dynamic loads acting on the lumbar spine. Consequently, it was the purpose of this research to assess the agreement between the static predictions made by 4D WATBAK and those from a comparable dynamic model. Six individuals were asked to perform a series of five lifting tasks, which ranged from lifting $2.5 \mathrm{~kg}$ to $22.5 \mathrm{~kg}$ and were designed to replicate the lifting component of the Work Capacity Assessment Test used within Australia. A single perpendicularly placed video camera was used to film each performance in the sagittal plane. The resultant two-dimensional kinematic data were input into the 4D WATBAK software and a dynamic biomechanical model to quantify the compression forces acting at the L4/L5 intervertebral joint. Results of this study indicated that as the mass of the load increased from $2.5 \mathrm{~kg}$ to $22.5 \mathrm{~kg}$, the static compression forces calculated by 4D WATBAK became increasingly less than those calculated using the dynamic model (mean difference ranged from $22.0 \%$ for $2.5 \mathrm{~kg}$ to $42.9 \%$ for $22.5 \mathrm{~kg}$ ). This study suggested that, for research purposes, a validated three-dimensional dynamic model should be employed when a task becomes complex and when a more accurate indication of spinal compression or shear force is required. Additionally, although it is clear that 4D WATBAK is particularly suited to industrial applications, it is suggested that the limitations of such modelling tools be carefully considered when task-risk and employee safety are concerned.
\end{abstract}

Key words: Spinal compression, lifting, manual material handling, 4D WATBAK, biomechanical model.

\section{INTRODUCTION}

Over the past three decades, several two- and threedimensional biomechanical models have been devised to quantify the various components of vertebral loading during a variety of manual handling tasks (Chaffin and Baker 1970; de Looze et al 1992; Kingma et al 1996). The first occupational model developed to estimate the loading on the lumbar spine was a two-dimensional linked-segment

Corresponding Author:

M. H. Cole

Biomechanics Laboratory, School of Health Sciences

University of South Australia, Adelaide, Australia

Tel: 61883026953 Fax: 61883026658

Email: Michael.cole@postgrads.unisa.edu.au model (LSM) that statically calculated the moment acting at each joint and the subsequent compression force on the spine (Chaffin and Baker 1970). However, according to previous research, model calculations that neglect the acceleration of body segments have the potential to underestimate the effect of the dynamic loads by between 18 and 67\% (McGill and Norman 1985; Milburn and Barrett 1996).

The 4D WATBAK software package (University of Waterloo, Ontario, Canada) is an advanced twodimensional modelling program designed to predict both the acute and cumulative loads on the lumbar spine during occupational activities, such as manual material handling (Neumann et al 1999). The program is equipped with a quasi-static two-dimensional linked-segment model, which is comprised of nine individual segments and it is used to assess symmetrical lifting activities performed in 
Table 1 The demographic characteristics of the research participants

\begin{tabular}{|c|c|c|c|c|c|c|c|c|}
\hline \multirow[b]{2}{*}{ Subject } & \multicolumn{3}{|c|}{ Male } & \multirow[t]{2}{*}{ Mean (SD) } & \multicolumn{3}{|c|}{ Female } & \multirow[t]{2}{*}{ Mean (SD) } \\
\hline & 1 & 3 & 5 & & 2 & 4 & 6 & \\
\hline Age (yrs) & 40 & 40 & 30 & $36.67(5.77)$ & 38 & 39 & 39 & $38.67(0.58)$ \\
\hline Mass (kg) & 70.6 & 91.4 & 84.4 & $82.1(10.58)$ & 59.2 & 51 & 55.4 & $55.20(4.10)$ \\
\hline Height (m) & 1.71 & 1.83 & 1.78 & $1.77(0.66)$ & 1.71 & 1.59 & 1.64 & $1.65(0.06)$ \\
\hline
\end{tabular}

the sagittal plane (Cholewicki et al 1991; Neumann et al 1999). Unlike other more simplified biomechanical models, 4D WATBAK has been designed to incorporate a considerable amount of anatomical detail for the low back extensor tissues and abdominal musculature in order to produce more realistic values for compression and shear forces (Norman et al 1999).

However, one of the underlying assumptions of the 4D WATBAK model is that a static analysis of human lifting reasonably estimates the magnitude of the moments, joint reaction forces and lumbar compression and shear forces during dynamic movements (Norman et al 1999). The implications of this assumption could effectively cause the risk associated with a task to be underestimated, as it has previously been argued that a static assessment of dynamic movement patterns does not represent the dynamic spinal loads (Freivalds et al 1984; McGill and Norman 1985).

Therefore, it was the purpose of this research to assess whether the static lumbar compression forces calculated using 4D WATBAK represent the dynamic lumbar compression forces calculated using an inverse dynamics approach. This was carried out for the lifting component of the Work Capacity Assessment Test (WCAT), which is used within some Australian industries as an effective return to work evaluation tool. This research has value for those professionals working within the health industry that are likely to utilise comprehensive risk assessment tools such as 4D WATBAK.

\section{METHODOLOGY}

\section{Subjects}

For the purposes of this research, the sample population was comprised of six individuals (demographic information included in Table 1), all of who expressed interest in the study and volunteered to perform the lifting component of the WCAT. The subjects were recruited from a variety of occupational backgrounds and were considered to be similar to the types of individuals that would be expected to perform such functional capacity evaluations within the workplace. Although all of these subjects were required to perform manual handling tasks as part of their occupation, none of them were explicitly employed as manual material handlers and, as such, had received no previous training or instruction on how to lift safely. The Divisional Ethics Committee for Health Sciences at the University of South Australia approved the experimental methodology of this research.

\section{Task}

The six subjects were asked to perform a series of five lifting tasks, which involved the lifting of a plastic box (height $\times$ width $\times$ depth $=0.29 \times 0.37 \times 0.37 \mathrm{~m}$ ) with a known mass from the floor to a bench top. Prior to each performance, the subjects were positioned at a standardised distance of $0.84 \mathrm{~m}$ behind the box, but were free to move themselves into a comfortable position to safely lift the load once testing had begun. After the box had been lifted from the floor, the subjects placed it onto a wooden bench (height $\times$ width $\times$ depth $=0.70 \times 0.41 \times 0.41 \mathrm{~m}$ ) that was positioned $0.32 \mathrm{~m}$ to their left. Following the initial lift of $2.5 \mathrm{~kg}$, an additional $5 \mathrm{~kg}$ weight (mass) was added to the box, after which the subjects were asked to repeat the performance lifting the $7.5 \mathrm{~kg}$ load. Similarly, the mass of the box was increased by a further $5 \mathrm{~kg}$ prior to each subsequent lift until the subjects withdrew or a maximum load of $22.5 \mathrm{~kg}$ was attained. In order to ensure that the weights (mass) were evenly distributed and secure throughout the duration of each performance, the added weights were placed onto a centrally located rod within the box. As the task was designed to closely replicate the lifting component of the WCAT, the lifting technique employed by the subjects was self-selected (i.e. no instruction was given). Similarly, the individual performances of the subjects were not governed by any temporal demands, as the pace at which the tasks were performed was not regulated in any way by the researchers.

\section{Data collection}

All subjects were required to wear flat-soled shoes and minimal clothing, to facilitate the accurate location of anatomical landmarks. Reflective markers were placed on the right side of each subject over the lateral aspect of the subjects' right shoe (fifth metatarsophalangeal joint); the lateral malleolus; the lateral epicondyle of the femur; the greater trochanter; the L4/L5 intervertebral joint; the spinous process of $\mathrm{T} 1$; the temporomandibular joint; the lateral border of the acromion; the lateral epicondyle of the humerus; and the ulnar styloid. Additionally, markers were located on the right and left edges of the bench top at $0.39 \mathrm{~m}$ apart, whilst the centre of the box was also marked. For the purposes of this analysis, this was considered to be the intersection point of two diagonal lines drawn on the facing surface of the box. Although the centre of the box did not depict the exact position of the centre of mass, it was considered to be a constant representation for between subject comparisons. The exact calculation 
of this centre of mass point during each of the different conditions would yield only small changes in vertical position during the early stages of the lift. During the testing procedure, all reflective markers were illuminated by two $500 \mathrm{~W}$ spotlights (Security Instruments, Maryland, USA).

Filming was carried out using a single Panasonic SVHS NV-MS5 video camera (Matsushita Electric Industrial Co Ltd., Osaka, Japan), operating at $50 \mathrm{~Hz}$ with a shutter setting of $1 / 500$ th of a second. The camera was located perpendicular to a line placed on the floor under the centre of the box (in its starting position) at a distance of $5.47 \mathrm{~m}$, whilst two reflective markers were positioned $0.69 \mathrm{~m}$ apart and used to facilitate the scaling of the calculated kinematic data.

\section{Data analysis}

\section{Two-dimensional kinematics}

The Peak Motus 2000 (Peak Performance Technologies Inc., Englewood, CO, USA) software was used to digitise the video and generate kinematic data. A full body linkedsegment model was used to determine angles (relative to the right horizontal) for the lower leg; the upper leg; the pelvis; the trunk; the head; the upper arm; and the forearm. Additionally, the centre of mass of each segment and whole body centre of mass was determined and represented by a virtual point within the model. The position of these virtual points was determined from the anthropometric data presented in Winter (1990). Finally, a quintic spline function (Woltring 1985) was applied to all raw coordinates in order to smooth the data and calculate kinematic quantities, such as linear and angular velocity and acceleration.

\section{Static lumbar compression forces}

For the purposes of calculating the static L4/L5 compression forces experienced during the lifts, the 4D WATBAK modelling software (University of Waterloo, Ontario, CA) was selected, as this software package has been used in some industrial settings around Australia. In order to calculate these forces, the model required the angular position of the major body segments, as well as the height and mass of each subject (Grills et al 1994; Neumann et al 1999; Schibye et al 2001). Using the estimated proportions of subject height, as described by Dreyfuss (1967), 4D WATBAK was able to estimate the length of each segment based on the value entered for subject height. Similarly, the software used the anthropometric data presented by Plagenhoef (1971) and Zatsiorsky and Seluyanov (1983) to estimate the mass of each body segment and establish the location of its centre of mass. For the purposes of this study, the kinematic data required to perform the static and dynamic calculations were extracted at five equally spaced periods throughout the first two-thirds of each lift, with the peak values presented in the results. For the purposes of this calculation, the lift was defined as beginning at the time that the load was first displaced in a vertical direction and finishing when the load first came into contact with the bench. As the bench was positioned to the side of the subjects (due to conformity with the guidelines of the lifting component of the WCAT) they were required to rotate their trunk at the end of the lift to place the load on the bench. As the peak compressive forces have been shown to occur in the first $150-200 \mathrm{~ms}$ (Gagnon and Smyth 1992) the researchers were confident that this rotational component would have little influence on the two-dimensional kinematics.

\section{Dynamic lumbar compression forces}

In order to establish whether the static lumbar compression forces provided a good representation of the dynamic lumbar compression forces, the dynamic two-dimensional model previously described by Chaffin and Andersson (1991) was employed. This model facilitated the calculation of the peak L4/L5 moment using standard Newtonian mechanics calculations, which were applied systematically backwards from the hands to the fourth lumbar vertebra. This model is comprised of seven segments, which include; the foot; the lower leg; the upper leg; the pelvis; the trunk; the upper arm and the forearm. In addition to this, the model utilises both trigonometric and anthropometric parameters to perform its calculations. The underlying formula is a development of the static moment equilibrium condition, which has been expanded to include the dynamic effects (Chaffin and Andersson 1991). This is shown in (1):

$$
\begin{aligned}
M_{\mathrm{j}}= & M_{\mathrm{j}-1}+\overline{\mathbf{j C M}}_{\mathrm{L}}\left(\cos \theta_{\mathrm{j}}\right) m_{\mathrm{Lg}} \\
& +\overline{\mathbf{j C M}}_{\mathrm{L}-1}\left(\cos \theta_{\mathrm{j}}\right) m_{\mathrm{L}} a_{\mathrm{L} y}+\overline{\mathbf{j C M}}_{\mathrm{L}}\left(\sin \theta_{\mathrm{j}}\right) m_{\mathrm{L}} a_{\mathrm{L} x} \\
& +\overline{j j-1}\left(\cos \theta_{\mathrm{j}}\right) R_{(\mathrm{j}-1) y} \\
& +\overline{j j-1}\left(\sin \theta_{\mathrm{j}}\right) R_{(\mathrm{j}-1) y}+I_{\mathrm{L}} \ddot{\theta}_{\mathrm{j}}
\end{aligned}
$$

where

$$
\begin{aligned}
& M_{\mathrm{j}} \quad \text { load moment at each joint (Nm). } \\
& M_{\mathrm{j}-1} \quad \text { load moment at adjacent joint }(\mathrm{j}-1)(\mathrm{Nm}) \text {. } \\
& \theta_{j} \text { postural angle of the joint }(j) \text { relative to the right } \\
& \text { horizontal axis }\left({ }^{\circ}\right) \text {. } \\
& m_{\mathrm{L}} \quad \text { mass of the link }(\mathrm{kg}) \text {. } \\
& \text { g gravitational acceleration }\left(\mathrm{m} \mathrm{s}^{-2}\right) \text {. } \\
& \overline{j j-1} \text { length of body segment links ( } \mathrm{j} \text { and } \mathrm{j}-1)(\mathrm{m}) \\
& \text { (Estimated from digitisation). } \\
& \overline{\mathrm{jCM}}_{\mathrm{L}} \quad \text { distance from joint (j) to link centre of mass (L) } \\
& \text { (Estimated from anthropometry). } \\
& \overline{\mathbf{j C M}}_{\mathrm{L}-1} \text { distance from adjacent joint (j-1) to adjacent } \\
& \text { link centre of mass }(\mathrm{L}-1)(\overline{\text { Estimated }} \text { from } \\
& \text { anthropometry). } \\
& a_{\mathrm{L} x} \text { or } a_{\mathrm{L} y} \quad \text { instantaneous linear acceleration }(x \text { or } y) \text { of link } \\
& \text { (L) at its centre of mass }\left(\mathrm{m} \mathrm{s}^{-2}\right) \text {. } \\
& \boldsymbol{R}_{(\mathrm{j}-1) \mathrm{y}} \quad \text { vertical component of the joint reaction force } \\
& \text { at the adjacent joint }(j-1)(\mathrm{N}) \text {. } \\
& \ddot{\theta}_{\mathbf{j}} \quad \text { angular acceleration of the link about joint (j) } \\
& \text { relative to horizontal axis }\left(\mathrm{rad} / \mathrm{s}^{2}\right) \text {. } \\
& I_{\mathrm{L}} \text { moment of inertia of link (L) about an axis } \\
& \text { through the centre of mass normal to the sagit- } \\
& \text { tal plane }\left(\mathrm{kg} \mathrm{m}^{2}\right) \text {. }
\end{aligned}
$$

In order to calculate the load on the lumbar spine using (1), the joint reaction force at the elbow and subsequently 
Table 2 The compression forces calculated by 4D WATBAK and the inverse dynamics model for the six subjects during the five lifts

\begin{tabular}{|c|c|c|c|c|c|c|c|c|c|c|}
\hline \multirow[t]{3}{*}{ Subject/lift } & \multicolumn{10}{|c|}{ L4/L5 Compression force (N) } \\
\hline & \multicolumn{2}{|c|}{$2.5 \mathrm{~kg}$} & \multicolumn{2}{|c|}{$7.5 \mathrm{~kg}$} & \multicolumn{2}{|c|}{$12.5 \mathrm{~kg}$} & \multicolumn{2}{|c|}{$17.5 \mathrm{~kg}$} & \multicolumn{2}{|c|}{$22.5 \mathrm{~kg}$} \\
\hline & Static & Dynamic & Static & Dynamic & Static & Dynamic & Static & Dynamic & Static & Dynamic \\
\hline 1 & 1673.1 & 2091.1 & 2393.4 & 3803.9 & 2737.3 & 4817.9 & 2736.3 & 4700.9 & 3326.8 & 6136.9 \\
\hline 2 & 1062.6 & 1259.7 & 2059.6 & 2715.1 & 2651.9 & 3984.1 & 2795.0 & 4929.8 & 3499.1 & 5826.8 \\
\hline 3 & 2838.4 & 3709.0 & 3263.7 & 5301.2 & 3768.5 & 7052.4 & 4321.2 & 8670.8 & 4577.6 & 8617.8 \\
\hline 4 & 1302.5 & 1811.4 & 1240.1 & 1738.4 & 2300.7 & 4527.1 & 2745.1 & 5831.5 & 2554.8 & 5482.9 \\
\hline 5 & 2501.4 & 3210.4 & 2876.7 & 3871.1 & 2695.4 & 4413.5 & 2881.3 & 4790.2 & 3228.9 & 5107.0 \\
\hline 6 & 1469.3 & 1895.7 & 1525.3 & 2135.5 & 2382.9 & 3428.8 & 2716.7 & 4264.0 & 2738.7 & 4188.0 \\
\hline Mean & 1807.9 & 2329.6 & 2226.5 & 3255.2 & 2756.1 & 4704.0 & 3032.6 & 5531.2 & 3321.0 & 5893.2 \\
\hline SD & 705.2 & 931.3 & 777.0 & 1317.0 & 526.6 & 1248.0 & 634.0 & 1621.9 & 713.5 & 1495.4 \\
\hline
\end{tabular}

the load moment at the elbow joint were calculated using the second condition of equilibrium for a dynamic approach (Nelkon and Parker 1971). This is shown in (2):

$$
F_{\mathrm{M}}=\frac{\left(\left(W_{1} \times W d_{1}\right)+\left(W_{2} \times W d_{2}\right)+(I \alpha)\right)}{d_{\mathrm{M}}}
$$

where

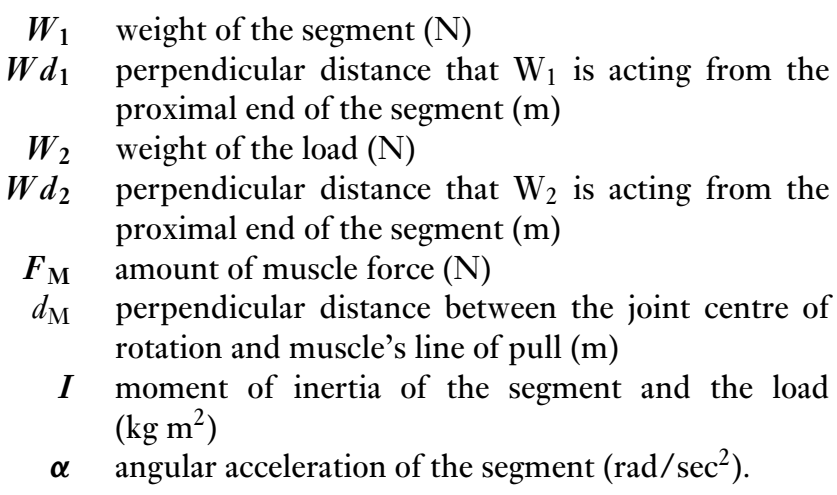

After the reaction force acting at the elbow had been calculated, trigonometry was used to resolve the vertical component, which was entered into (1) as the value for $\boldsymbol{R}_{(\mathrm{j}-1) y}$. The estimated joint reaction force was then used to calculate the load moment acting at the elbow joint, which was entered into (1) as the value for $\boldsymbol{M}_{\mathbf{j}-1}$ for the subsequent calculation of the moment acting at the shoulder. Similarly, the moment calculated for the shoulder joint was then used to determine the joint reaction force and subsequently the vertical component of this force. This information could then be input into (1), such that the load moment acting at the L4/L5 intervertebral joint could eventually be determined.

As previously indicated, research suggests that dynamic estimates of shear and compression forces provide a better representation of the true forces acting on the joints of the body (e.g. McGill and Norman 1985). However, it is important to acknowledge that the dynamic model described by Chaffin and Andersson (1991) comprised considerably less anatomical detail when compared to the 4D WATBAK model. As such, it may be important to consider this factor when reviewing the dynamic data and any comparisons that are made with the static approach.

\section{Statistical analysis}

For the purposes of assessing the relationship between the statically- and dynamically-determined compression forces, a Pearson's Product Moment Correlation Coefficient was calculated using the SPSS 11.0 statistics package for Windows (SPSS Inc., Chicago, IL, USA), with a significance level set at $p \leq 0.05$. Based on the recommendations of Vincent (1999), a calculated $r$-value for the correlation coefficient was considered to be low when it was between 0.5 and 0.7 ; moderate when it was between 0.7 and 0.8 ; and high when it was $\geq 0.9$. However, it is important to clarify that the small sample size used in this research $(n=$ 6 subjects) is probably not sufficient to establish statistical significance and without a power analysis, it is difficult to interpret the effectiveness of this result. However, within the field of applied biomechanics, data collection and processing for a single subject can take a considerable amount of time ( $>10 \mathrm{~h}$ per subject in this case), which can often make it unfeasible to include large subject numbers. Hence, the reader is cautioned as to the interpretation of the statistical significance of these results (Table 2).

\section{RESULTS}

The results of this investigation show that the static compression forces (4D WATBAK) underestimate the dynamic compression forces (inverse dynamics calculations) in all lifts from the $2.5 \mathrm{~kg}$ lift $(\overline{\mathrm{x}}=22.0 \pm 4.1 \%)$ to the $22.5 \mathrm{~kg}$ lift $(\overline{\mathrm{x}}=42.9 \pm 7.1 \%)$. A Pearson's Product Moment Correlation Coefficient was used to assess the relationship between the mass of the load lifted and the extent to which the static predictions underestimated the dynamic loads. The results of this test identified a statistically significant positive relationship between the load's mass and the percentage error in prediction $(r=0.768, p<0.01)$, which indicates a greater percentage deficit (underestimation) as the mass of the load was increased (see Figures 1 and 2). 


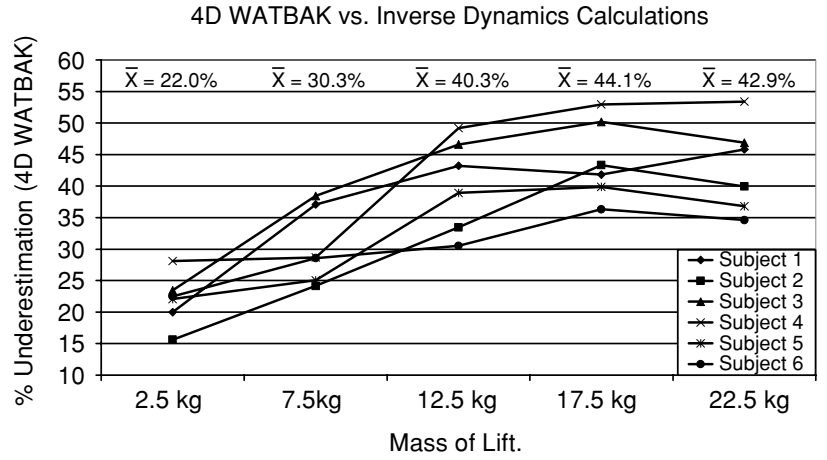

Figure 1 Results of the comparison made between 4D WATBAK and the inverse dynamics model. Each line represents the results for a single subject, with a positive percentage indicating that the static predictions of $4 \mathrm{D}$ WATBAK were less than the dynamic forces. The mean values shown in this figure represent the average percentage by which $4 \mathrm{D}$ WATBAK underestimated the dynamic model for each mass.

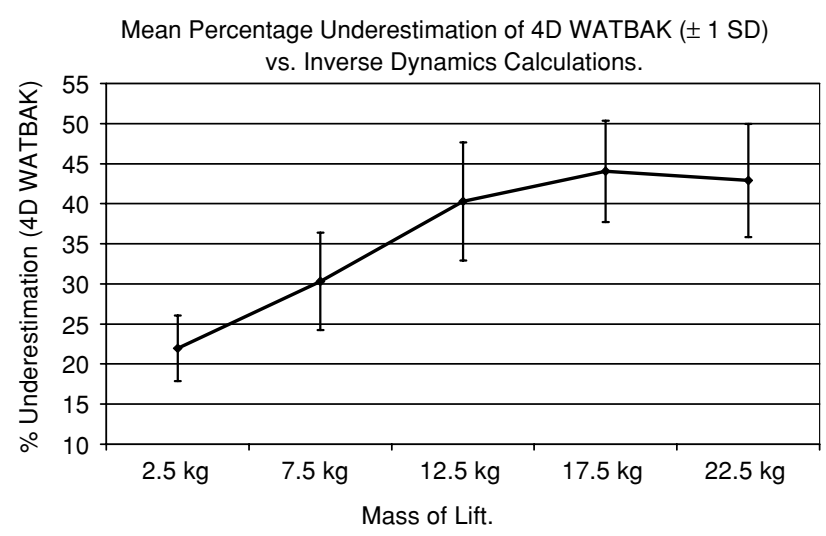

Figure 2 Mean percentage underestimation between 4D WATBAK and the inverse dynamics calculations, with \pm 1 standard deviation bars shown. The graph clearly shows as the load increased, the percentage error also increased.

\section{DISCUSSION}

It is clear from the results that the 4D WATBAK modelling software underestimated the lumbar compression forces when compared to the values from inverse dynamics calculations. The degree of underestimation observed in this analysis is comparable with previous work performed by McGill and Norman (1985), Freivalds et al (1984) and Milburn and Barrett (1996) who reported a 18 and $67 \%$ increase in the compressive loads measured using a dynamic approach, respectively. The increasing trend of underestimation demonstrated by 4D WATBAK may have important implications when risk assessment is made within industry using safe lifting limits such as the ones provided by the NIOSH (1981) guidelines or the gender- and age-specific lifting limits proposed by Jäger and Luttman (1997). Although it can be argued that acute (single) compressive loading on the spine in this manner alone will not cause back injuries (Adams and Dolan 1995) it is still important to point out such a wide ranging and unusual underestimation. With this in mind, however, it is important to acknowledge that with an increase in load, it would be expected that the dynamic component of the lift (i.e. the acceleration) would decrease and thus the predictions from the two methods would become closer. As this trend was not observed within the current investigation, it is possible that the increased discrepancy identified between the two models was due to other factors, such as differences in anthropometries and kinematics.

Despite the fact that current research (Straker et al 2004) is moving away from the use of safe lifting limits that are finite in nature (such as NIOSH (1981) and Jäger and Luttman (1997)) and more towards a comprehensive risk assessment with the subsequent use of participative ergonomics intervention, there is still merit in demonstrating a potential issue with a modelling tool that may be used in industrial applications to support some part of such a risk assessment.

Nevertheless, in this context, it is important for the limitations of the research conducted in this study to be identified for the reader. First, the inverse dynamics calculations employed were two-dimensional, whilst the actions performed by the subjects in lifting these masses were not (the subjects rotated as they placed the box onto the table). Although it can be argued that 4D WATBAK is capable of calculating the three-dimensional forces acting on the spine, it was considered that the time and equipment required for such an analysis would cause industrial risk assessors to have no choice but to use the twodimensional option. Secondly, the subjects were not age, mass and anthropometrically matched and they were all allowed to adopt their choice of lifting technique. This could have potentially caused discrepancies in the results, which could have possibly been avoided in a case where the lifting method was carefully controlled. Thirdly, although 4D WATBAK provided estimates that were considerably less than the inverse dynamics model, it is feasible that the lack of anatomical detail possessed by the inverse dynamics model may have caused its predictions to be higher than the true compressive loads. Consequently, it is possible that the true compression forces acting on the lower spine lie somewhere between the two estimates and this is an important factor to consider when considering the implications of these findings. Finally, despite the fact that the 4D WATBAK software may underestimate the loads on the spine when compared to inverse dynamics techniques, it may also be the case that the compression forces experienced during such lifting tasks are still within the safe lifting limits for all workers.

In summary, it is clear that there may be a concern with using 4D WATBAK to accurately assess specific compressive loads on the lumbar spine during lifting. Inverse dynamics may provide a more accurate (although still an estimation) measure of spinal compressive loading during lifting, but it is obvious that three-dimensional methods 
should be used. It is a concern that specific safe lifting limits such as NIOSH (1981) and Jäger and Luttman (1997) are still being used to provide almost total risk assessment in some applications particularly when these limits may be totally incorrect and indeed inappropriate to the task. However, it should be noted that this latter point is beginning to be change with industrial ergonomic applications of risk assessment being advocated within recent literature (Straker et al 2004). Additionally, it is evident that any attempt to conduct inverse dynamics calculations (two-dimensional or three-dimensional) for industrial applications of lifting or indeed of risk assessment would be unrealistic due to the time-consuming nature, complexity and equipment required to perform this type of analysis. Therefore, until further research involving more subjects is conducted under controlled lifting conditions, 4D WATBAK may be the only suitable tool for an easy estimation of spinal loading during lifting in an industrial setting. It is suggested that future research should aim to develop and promote multi-faceted risk assessment methods for industrial applications.

\section{ACKNOWLEDGMENTS}

The authors would like to thank Valerie O'Keeffe and Lyn Barnett, Workplace Services, Adelaide, Australia.

\section{REFERENCES}

Adams MA, Dolan P. 1995. Recent advances in lumbar spinal mechanics and their clinical significance. Clin Biomech, 101:3-19.

Chaffin DB, Andersson GBJ. 1991. Occupational biomechanical models. In Occupational biomechanics. New York: John Wiley \& Sons, Inc. p 170-263.

Chaffin DB, Baker WH. 1970. A biomechanical model for analysis of symmetric sagittal plane lifting. AIIE Trans, 21:16-27.

Cholewicki J, McGill SM, Norman RW. 1991. Lumbar spine loads during the lifting of extremely heavy weights. Med Sci Sports Exercise, 2310:1179-1186.

de Looze MP, Kingma I, Bussmann JBJ, Toussaint HM. 1992. Validation of a dynamic linked segment model to calculate joint moments in lifting. Clin Biomech, 7:161-169.

Dreyfuss H. 1967. The measure of man: Human factors in design. New York: Whitney Library of Design.

Freivalds A, Chaffin DB, Garg A, Lee KS. 1984. A dynamic biomechanical evaluation of lifting maximum acceptable loads. 7. Biomech, 174:251-262.

Gagnon M, Smyth G. 1992. Biomechanical exploration on dynamic modes of lifting. Ergonomics, 353:329-345.

Grills PM, Wells RP, Norman RW. 1994. Variability of low back loads from a biomechanical model. VIIIth Biennial Conference, Calgary, Canadian Society of Biomechanics.
Hannah J, Hillier M. 1978. Applied mechanics. London: Pitman Publishing Ltd.

Hay JG. 1973. The biomechanics of sports technique. Englewood Cliffs, NJ: Prentice-Hall.

Jäger M, Luttman A. 1997. Assessment of low-back load during manual materials handling. 13th Triennial Congress of the International Ergonomics Association, Tampere, Finland, Finnish Institute of Occupational Health.

Kingma I, de Looze MP, Toussaint HM, Klijnsma JG, Bruijnen TBM. 1996. Validation of a full body 3-D dynamic linked segment model. Hum Movement Sci, 156:833-860.

LeVeau BF. 1992. Williams \& Lissner's biomechanics of human motion. Philadelphia: WB Saunders.

McGill SM, Norman RW. 1985. Dynamically and statically determined low back moments during lifting. 7 Biomech, 1812:877-885.

Milburn P, Barrett R. 1996. Spinal loads in occupational bedmaking: effect of external and inertial forces. First Australasian Biomechanics Conference, Sydney, University of Sydney.

National Institute for Occupational Safety and Health. 1981. A Work Practices Guide for Manual Lifting. Cincinnati, OH: US Department of Health and Human Services, NIOSH.

Nelkon M, Parker P. 1971. Static bodies: Fluids. In advanced level physics. London: Heinemann Educational Books. p 96-124.

Neumann WP, Wells RP, Norman R. 1999. 4D WATBAK: Adapting research tools and epidemiological findings to software for easy application by industrial personnel. International Conference on Computer-Aided Ergonomics and Safety, Barcelona, Spain.

Norman R, Wells RP, McGill SM. 1999. 4D WATBAK: User's Manual. Waterloo, Canada: Faculty of Applied Health Sciences, University of Waterloo.

Plagenhoef S. 1971. Patterns of human motion: A Cinematographic analysis. New Jersey: Prentice-Hall, Inc.

Poppen NK, Walker PS. 1978. Forces at the glenohumeral joint in abduction. Clin Orthop, 135:165-170.

Schibye B, Søgaard K, Martinsen D, Klausen K. 2001. Mechanical load on the low back and shoulders during pushing and pulling of two-wheeled waste containers compared with lifting and carrying of bags and bins. Clin Biomech, 16:549-559.

Straker L, Burgess-Limerick R, Pollock C, Egeskov R. 2004. A randomized and controlled trial of a participative ergonomics intervention to reduce injuries associated with manual tasks: Physical risk and legislative compliance. Ergonomics, 472:166-188.

Vincent WJ. 1999. Statistics in kinesiology. Champaign, IL: Human Kinetics.

Winter DA. 1990. Biomechanics and motor control of human movement. New York: John Wiley \& Sons Inc.

Woltring HJ. 1985. On optimal smoothing and derivative estimation from noisy displacement data in biomechanics. Hum Movement Sci, 43:229-245.

Zatsiorsky V, Seluyanov V. 1983. The mass and inertia characteristics of the main segments of the human body. In Matsui H, Kobayashi K. Biomechanics VIII-B. Champaign, IL: Human Kinetics Publishers. p 1152-1159. 


\section{APPENDICES}

\section{Calculation of the joint reaction force at the $14 / 15$ joint (inverse dynamics model)}

In order to calculate the load on the lumbar spine using (1), it is first necessary to calculate the joint reaction force at the elbow and subsequently the moment at the elbow. The value calculated for the moment at the elbow joint is entered into (1) as the value for $\boldsymbol{M}_{\mathbf{j}-1}$, which is representative of the moment at the adjacent joint to the shoulder. The calculation of the moment at the elbow can be performed using the second condition of equilibrium (2), as during this task, the forearm is not subject to a Coriolis force due to the fact that it is has no other segment or object attached to its distal end (Chaffin and Andersson 1991). The following pages outline the calculation procedure that is required in order to attain the final load on the L4/L5 intervertebral joint during the performance of a $22.5 \mathrm{~kg}$ lift.

$$
\begin{aligned}
M_{\mathbf{j}}= & M_{\mathbf{j}-1}+{\overline{\mathbf{j} C M_{L}}}_{\left(\cos \theta_{\mathrm{j}}\right) m_{\mathrm{Lg}}+\overline{\mathbf{j C M}}_{\mathrm{L}-1}\left(\cos \theta_{\mathrm{j}}\right)} \\
& \times m_{\mathrm{L}} a_{\mathrm{L} y}+\overline{\mathbf{j C M}}_{\mathrm{L}}\left(\sin \theta_{\mathrm{j}}\right) m_{\mathrm{L}} a_{\mathrm{L} x}+\overline{j j-1} \\
& \times\left(\cos \theta_{\mathrm{j}}\right) R_{(\mathrm{j}-1) y}+\overline{j j-1}\left(\sin \theta_{\mathrm{j}}\right) R_{(\mathrm{j}-1) y}+I_{\mathrm{L}} \ddot{\theta}_{\mathrm{j}}
\end{aligned}
$$

(Derived from Chaffin and Andersson 1991) where

$$
\begin{aligned}
& M_{\mathrm{j}} \quad \text { load moment at each joint }(\mathrm{Nm}) \\
& M_{\mathrm{j}-1} \quad \text { load moment at adjacent joint }(\mathrm{j}-1)(\mathrm{Nm}) \\
& \theta_{\mathrm{j}} \quad \text { postural angle of the joint }(\mathrm{j}) \text { relative to the right } \\
& \text { horizontal axis }\left({ }^{\circ}\right) \\
& m_{\mathrm{L}} \quad \text { mass of the link }(\mathrm{kg}) \\
& \text { g gravitational acceleration }\left(\mathrm{m} . \mathrm{s}^{-2}\right) \\
& \overline{j j-1} \text { length of body segment links (j and } \mathrm{j}-1)(\mathrm{m}) \\
& \text { (Estimated from digitisation) } \\
& \overline{\mathbf{j C M}}_{\mathrm{L}} \text { distance from joint (j) to link centre of mass (L) } \\
& \text { (Estimated from anthropometry) } \\
& \overline{\mathbf{j C M}}_{\mathrm{L}-1} \text { distance from adjacent joint }(\mathrm{j}-1) \text { to adjacent }
\end{aligned}
$$

\section{Determination of the joint reaction force at the elbow}

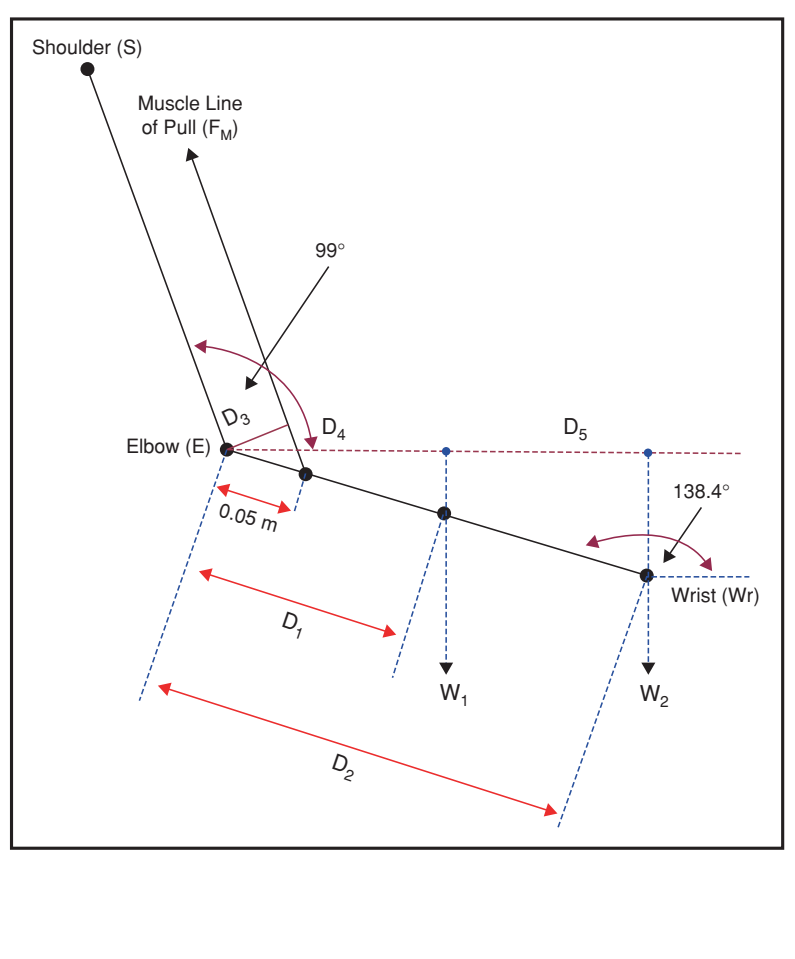

Note: All distances are taken from the joint centre of rotation of the elbow joint, whilst the muscle's line of pull is considered to be parallel to the upper arm segment. Additionally all of the identified angles have been determined from the kinematic data set of the study (i.e. digitisation).

\section{Relevant subject information}

Mass of the Athlete $=91.40 \mathrm{~kg}$

Length of Forearm $\left(D_{2}\right)=0.236 \mathrm{~m}$

Mass of Forearm $=91.40 \times 0.022$ (anthropometric constant) $=2.011 \mathrm{~kg}$

Weight of Forearm $\left(W_{1}\right)=2.011 \times 9.81$ (acceleration due to gravity) $=19.73 \mathrm{~N}$

Weight of the $\operatorname{Load}\left(W_{2}\right)=22.50 \times 9.81$ (acceleration due to gravity) $=220.73 \mathrm{~N}$

Joint to Centre of Mass $\left(D_{1}\right)=0.236 \times 0.682$ (constant from proximal) $=0.161 \mathrm{~m}$.

The anthropometric constants used to calculate the mass of the forearm and the location of the segment centre of mass were taken from the anthropometric data presented by Winter (1990). Additionally, the length of the forearm and the angles depicted in the figures were taken from the kinematic data set obtained through the video digitisation of this lift, whilst the mass of the forearm and the load were multiplied by the acceleration that occurred due to the earth's gravity $\left(9.81 \mathrm{~m} . \mathrm{s}^{-2}\right)$ in order to calculate their respective weights. 
Determination of the perpendicular distance between the elbow and the muscle's line of pull $\left(D_{3}\right)$

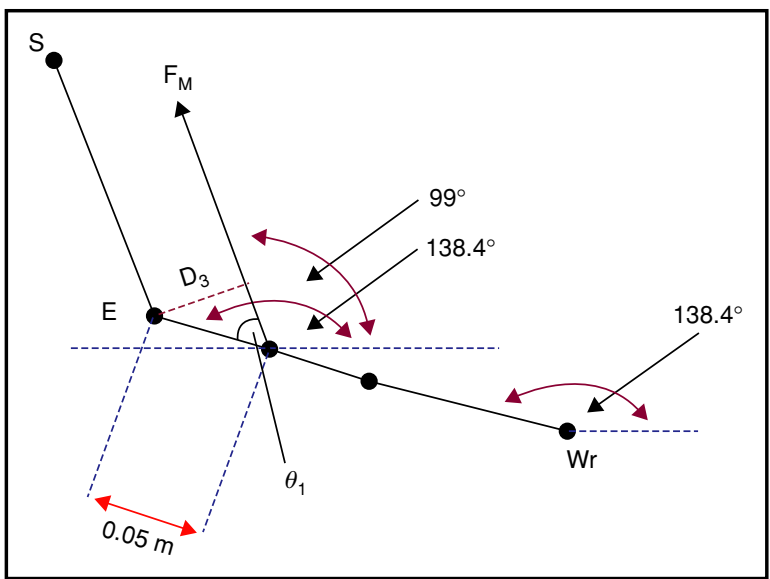

$\theta_{1}=138.4^{\circ}-99^{\circ}=39.4^{\circ}$

$\sin \theta_{1}=\frac{\text { opp }}{\text { hyp }}$

$\therefore \sin 39.4^{\circ}=\frac{D_{3}}{0.05}$

$\therefore D_{3}=0.032 \mathrm{~m}$

Determination of the perpendicular distance between the elbow and the forearm $\operatorname{COM}\left(D_{4}\right)$
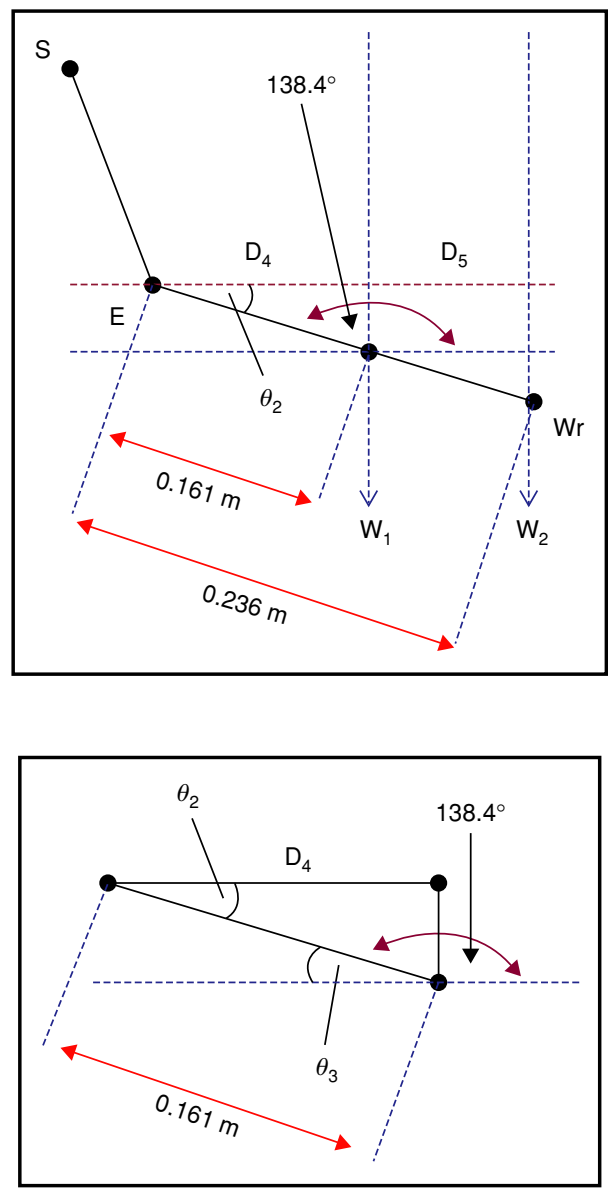

$$
\theta_{3}=180^{\circ}-138.4^{\circ}=41.6^{\circ}
$$

As $\theta_{3}$ is equal to $41.6^{\circ}$, the angle defined as $\theta_{2}$ is also $41.6^{\circ}$ due to the relationship that exists for alternate angles between two parallel lines.

$$
\begin{aligned}
& \cos \theta_{2}=\frac{\mathrm{adj}}{\mathrm{hyp}} \\
& \therefore \cos 41.6^{\circ}=\frac{D_{4}}{0.161} \\
& \therefore D_{4}=0.120 \mathrm{~m}
\end{aligned}
$$

Determination of the perpendicular distance between the elbow joint and the load $\left(D_{5}\right)$

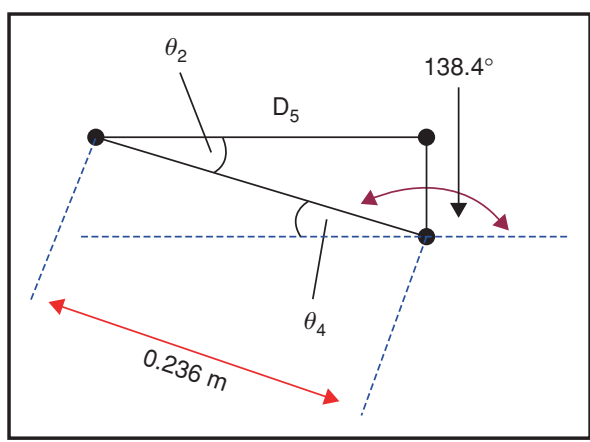

$$
\theta_{4}=180^{\circ}-138.4^{\circ}=41.6^{\circ}
$$

As $\theta_{4}$ is equal to $41.6^{\circ}$, the angle defined as $\theta_{2}$ is also $41.6^{\circ}$ due to the relationship that exists for alternate angles between two parallel lines.

$$
\begin{aligned}
& \cos \theta_{2}=\frac{\mathrm{adj}}{\mathrm{hyp}} \\
& \cos 41.6^{\circ}=\frac{D_{5}}{0.236} \\
& D_{5}=0.177 \mathrm{~m}
\end{aligned}
$$

Determination of the moment of inertia of the forearm segment and the $22.5 \mathrm{~kg}$ mass

Segment

$$
\begin{aligned}
I=m k^{2}+I_{\text {Cof G constant } m} & =2.01 \mathrm{~kg} \\
k & =0.236 \times 0.827(\text { constant from } \\
& \text { proximal })=0.195 \mathrm{~m} \\
& \\
I_{\text {Cof G constant }}= & 0.0075 \mathrm{~kg} \mathrm{~m}^{2}(\text { Hay, 1973). }
\end{aligned}
$$

The radius of gyration used to determine $k$ represents the percentage of the segment distance from the proximal end and was obtained from the anthropometric data presented by Winter (1990). Alternatively the centre of gravity constant was derived from the data presented by Hay (1973), who expressed this constant in slugs- $\mathrm{ft}^{2}$. This value was converted to $\mathrm{kg} \mathrm{m}^{2}$ for this application.

$$
\begin{aligned}
& \therefore I=2.01 \times(0.195)^{2}+0.0075 \\
& \therefore I=0.084 \mathrm{~kg} \mathrm{~m}^{2}
\end{aligned}
$$


Mass

$$
\begin{aligned}
& I=\mathrm{md}^{2} \quad \mathrm{~m}=22.5 \mathrm{~kg} \\
& d=0.236 \mathrm{~m} \\
& \therefore I=22.5 \times(0.236)^{2} \\
& \therefore I=1.253 \mathrm{~kg} \mathrm{~m}{ }^{2}
\end{aligned}
$$

Note: It should be acknowledged that when calculating the moment of inertia for a mass such as the one used during this lifting position/activity that the value of $d$ represents the distance to the handles of the mass and not strictly the mass's centre of gravity.

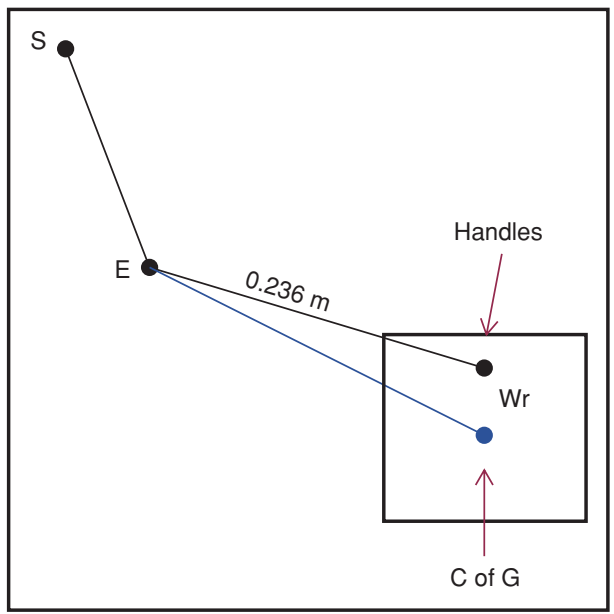

\section{Total moment of inertia}

$$
I=1.253+0.084=1.337 \mathrm{~kg} \mathrm{~m}^{2}
$$

Using the second condition of equilibrium.

$$
\Sigma C W M+\Sigma A C W M+I \alpha=0
$$

where

$\Sigma C W M \quad$ is the sum of the clockwise moments (which are assigned a negative component).

$\Sigma A C W M$ is the sum of the anti-clockwise moments (which are assigned a positive component).

$I \quad$ is the moment of inertia of the segment and any external load $\left(\mathrm{kg} \mathrm{m}^{2}\right)$.

$\alpha$ is the angular acceleration of the segment $\left(\mathrm{rad} / \mathrm{sec}^{2}\right)$.

$$
\begin{aligned}
\therefore & \left(-\left(\left(W_{1} \times D_{4}\right)+\left(W_{2} \times D_{5}\right)\right)\right)+\left(F_{M} \times D_{3}\right) \\
& +(-(I \alpha))=0 \\
\therefore & (-((19.73 \times 0.120)+(220.73 \times 0.177))) \\
& +\left(F_{M} \times 0.032\right)+(-(1.337 \times 5.343))=0
\end{aligned}
$$

Note: Moment of inertia is defined as the resistance of an object to start or continue rotating about a known axis; in this case the elbow joint. In this example the forearm was rotating in a clockwise direction. As this movement needed to be actively controlled, it required an eccentric contraction of the biceps, which would have contributed to the muscle force and consequently the joint reaction force at the elbow (hence it is given a negative component).

$$
\begin{aligned}
& \therefore F_{M}=\frac{41.437+7.144}{0.032} \\
& \therefore F_{M}=1518.16 \mathrm{~N}
\end{aligned}
$$

As the forearm was not subject to the effect of any external forces, the magnitude of the muscle force $\left(F_{\mathrm{M}}\right)$ calculated using the second condition of equilibrium was considered to be equal to the joint reaction force acting at the elbow (LeVeau 1992). However, in order to calculate the reactive force for the shoulder and subsequent joints, the $M_{\mathrm{j}-1}$ value (which is a moment) is required for (1) and needs to be calculated. In order to accomplish this, the calculated joint reaction force (muscle force in this case) at the elbow needs to be adjusted by applying it to the following equation:

$$
\begin{aligned}
& \text { Moment }=\text { Force }(F M) \times \text { Perpendicular distance } \\
& \therefore \text { Moment }=1518.16 \times 0.032=48.58 \mathrm{Nm}
\end{aligned}
$$

\section{Determination of the vertical component of joint} reaction force $\left(R_{(j-1) y}\right)$

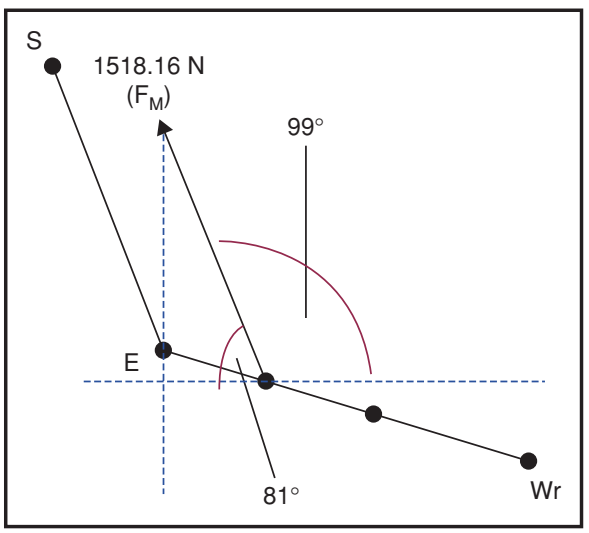

Note: For the purposes of calculating the load at the L4/L5 intervertebral joint, (1) only requires the vertical component of the joint reaction force estimated for the elbow.

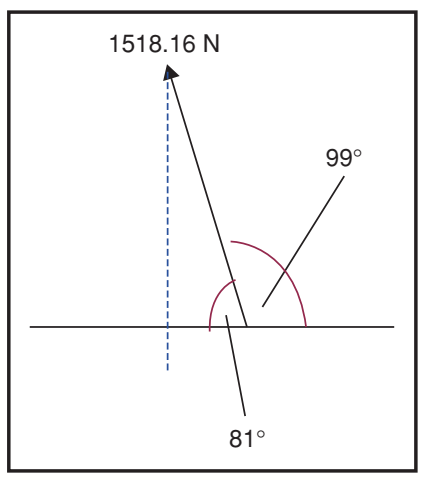

\section{Resolve vertically}

$$
\begin{aligned}
& R(\mathrm{j}-1)_{y}=F_{\mathrm{M}} \sin 81^{\circ} \\
& \therefore R_{(\mathrm{j}-1) y}=1518.16 \times 0.9877=1499.48 \mathrm{~N}
\end{aligned}
$$




\section{Determination of the moment of inertia of the upper arm (segment)}

$$
I=m k^{2}+I_{\mathrm{C} \text { of G constant }}
$$

Note: For the calculation of the moment of inertia, (1) requires the radius of gyration $(k)$ to be replaced with the location of the segment centre of mass $(d)$ (Chaffin and Andersson 1991).

$$
\begin{aligned}
\therefore I=\mathrm{md}^{2}+I_{\mathrm{C} \text { of G constant } m} m= & 91.40 \times 0.028 \\
& (\text { anthropometric constant }) \\
= & 2.56 \mathrm{~kg} \\
= & 0.305 \times 0.436(\text { constant } \\
d & \text { from proximal }) \\
= & 0.133 \mathrm{~m} \\
I_{\text {Cof G constant }}= & 0.021 \mathrm{~kg} \mathrm{~m}^{2}(\text { Hay }, 1973)
\end{aligned}
$$

$\therefore I=2.56 \times(0.133)^{2}+0.021$

$\therefore I=0.066 \mathrm{~kg} \mathrm{~m}^{2}$

\section{Angular acceleration}

$$
\ddot{\theta}_{\mathrm{j}}=7.249 \mathrm{rad} / \mathrm{s}^{2}
$$

Note: In this position, the upper arm was moving in an anti-clockwise direction, accelerating both vertically and anteriorly, which would require this segment to overcome the effects of inertia and consequently add to the required muscle force. Again, this is related to the fact that this movement or rotation or the upper arm is actively controlled by the surrounding musculature.

\section{Determination of the moment at the shoulder joint}

Given the information obtained in the previous calculations, the moment acting at the shoulder joint can now be calculated using (1).

$$
\begin{aligned}
M_{\mathrm{j}}= & M_{\mathrm{j}-1}+\overline{\mathbf{j C M}}_{\mathrm{L}}\left(\cos \theta_{\mathrm{j}}\right) m_{\mathrm{Lg}}+\overline{\mathbf{j C M}}_{\mathrm{L}-1}\left(\cos \theta_{\mathrm{j}}\right) \\
& \times m_{\mathrm{L}} a_{\mathrm{L} y}+\overline{\mathbf{j C M}}_{\mathrm{L}}\left(\sin \theta_{\mathrm{j}}\right) m_{\mathrm{L}} a_{\mathrm{L} x}+\overline{j j-1}\left(\cos \theta_{\mathrm{j}}\right) \\
& \times R_{(\mathrm{j}-1) y}+\overline{j j-1}\left(\sin \theta_{\mathrm{j}}\right) R_{(\mathrm{j}-1) y}+I_{\mathrm{L}} \ddot{\theta}_{\mathrm{j}}
\end{aligned}
$$

(Derived from Chaffin and Andersson 1991) where

\footnotetext{
$M_{\mathrm{j}} \quad$ load moment at each joint $(\mathrm{Nm})$

$M_{\mathrm{j}-1} \quad$ load moment at adjacent joint $(\mathrm{j}-1)(\mathrm{Nm})$

$\theta_{j} \quad$ postural angle of the joint $(\mathrm{j})$ relative to the right horizontal axis $\left(^{\circ}\right)$

$m_{\mathrm{L}} \quad$ mass of the link $(\mathrm{kg})$

$\mathrm{g}$ gravitational acceleration $\left(\mathrm{m} \mathrm{s}^{-2}\right)$

$\overline{j j-1}$ length of body segment links ( $\mathrm{j}$ and $\mathrm{j}-1)(\mathrm{m})$ (Estimated from digitisation)

$\overline{\mathbf{j C M}}_{\mathrm{L}} \quad$ distance from joint (j) to link centre of mass (L) (Estimated from anthropometry)

$\overline{\mathbf{j C M}}_{\mathrm{L}-1}$ distance from adjacent joint $(\mathrm{j}-1)$ to adjacent link centre of mass $(\mathrm{L}-1)(\overline{\text { Estimated }}$ from anthropometry)

$a_{\mathrm{L} x}$ or $a_{\mathrm{L} y} \quad$ instantaneous linear acceleration ( $x$ or $\left.y\right)$ of link (L) at its centre of mass $\left(\mathrm{m} . \mathrm{s}^{-2}\right)$
}

$R_{(\mathrm{j}-1) y} \quad$ vertical component of the joint reaction force at the adjacent joint $(\mathrm{j}-1)(\mathrm{N})$

$\ddot{\theta}_{\mathrm{j}} \quad$ angular acceleration of the link about joint (j) relative to horizontal axis $\left(\mathrm{rad} / \mathrm{s}^{2}\right)$

$I_{\mathrm{L}}$ moment of inertia of link (L) about an axis through the centre of mass normal to the sagittal plane $\left(\mathrm{kg} \mathrm{m}^{2}\right)$

\section{Substitute values into the equation}

$$
\begin{aligned}
\therefore M_{\mathrm{j}}= & 48.58+\left(0.133\left(\cos 81^{\circ}\right)(2.55 \times 9.81)\right) \\
& +\left(0.161\left(\cos 81^{\circ}\right)(2.55 \times+1.011)\right) \\
& +\left(0.133\left(\sin 81^{\circ}\right)(2.55 \times+0.055)\right) \\
& +\left((0.305 \times 0.236)\left(\cos 81^{\circ}\right)(1499.48)\right) \\
& +\left(0.305 \times 0.236\left(\sin 81^{\circ}\right)(1499.48)\right) \\
& +(0.066 \times 7.249) \\
\therefore M_{\mathrm{j}}= & 48.58+0.521+0.065+0.018+16.884 \\
& +106.604+0.478=173.15 \mathrm{Nm}
\end{aligned}
$$

Note: The horizontal $\left(a_{\mathrm{L} x}\right)$ and vertical $\left(a_{\mathrm{L} y}\right)$ components of the linear velocity were both assigned a positive direction, as the mass was being moved closer to the body and upwards. There was a need in this situation, to control the movement of the mass, which would have contributed to the muscle force and loading at the shoulder joint.

Determination of the vertical component of the joint reaction force at the shoulder $\left(R_{(j-1) y}\right)$

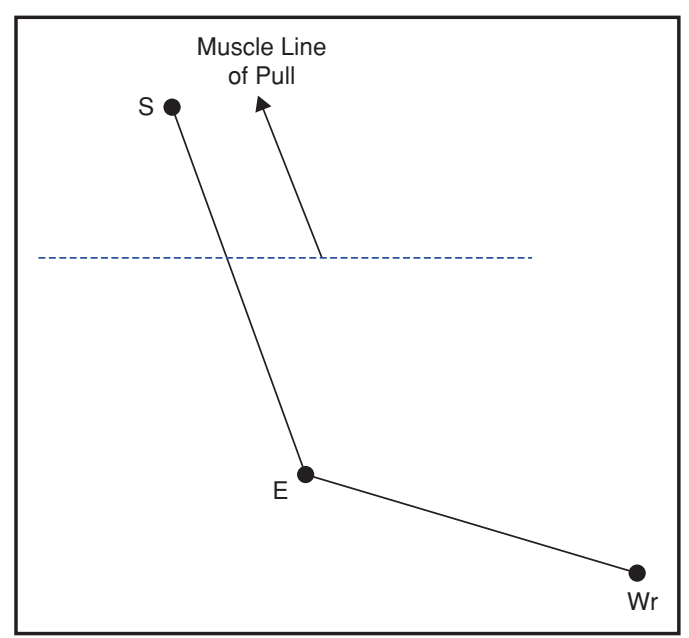

Assumption: For the purposes of this calculation procedure, it was assumed that the line of pull of the musculature acting around the shoulder joint was parallel to the upper arm segment and that this musculature inserted at a distance of 0.05 $\mathrm{m}$ from the joint centre of rotation (Poppen and Walker 1978). 


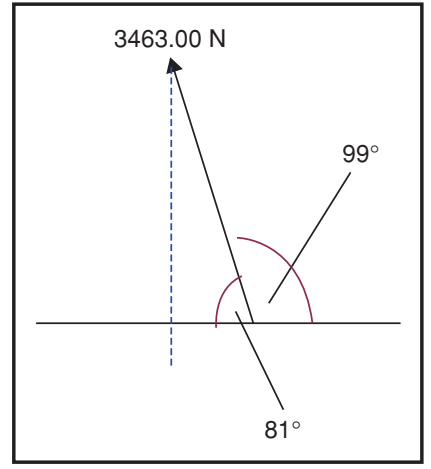

\section{Resolve vertically}

$$
\begin{aligned}
& F_{\mathrm{M}}=\frac{173.15}{0.05 \text { (assumed) }} \quad F_{\mathrm{M}}=3463.00 \mathrm{~N} \\
& \therefore R_{(\mathrm{j}-1) y}=F_{\mathrm{M}} \sin 81^{\circ} \\
& \therefore R_{(\mathrm{j}-1) y}=3463.00 \times 0.9877=3420.40 \mathrm{~N}
\end{aligned}
$$

\section{Moment of inertia of the trunk}

$$
I=m k^{2}+\mathrm{I}_{\mathrm{C} \text { of } \mathrm{G} \text { constant }}
$$

Note: For the calculation of the moment of inertia, (1) requires the radius of gyration $(k)$ to be replaced with the location of the segment centre of mass $(d)$.

$$
\begin{aligned}
\therefore I=m d^{2}+I_{\text {Cof G constant }} m & =91.40 \times 0.355 \\
& (\text { anthropometric constant }) \\
= & 32.45 \mathrm{~kg} \\
= & 0.431 \times 0.630 \\
& (\text { constant from proximal }) \\
= & 0.272 \mathrm{~m} \\
I_{\text {Cof G constant }}= & 1.261 \mathrm{~kg} \mathrm{~m}^{2}(\text { Hay }, 1973)
\end{aligned}
$$$$
\therefore I=32.45 \times(0.272)^{2}+1.261
$$$$
\therefore I=3.654 \mathrm{~kg} \mathrm{~m}^{2}
$$

\section{Angular acceleration}

$$
\ddot{\theta}_{\mathrm{j}}=10.86 \mathrm{rad} / \mathrm{s}^{2}
$$

Note: In this position, the trunk was flexing forward and consequently moving in a clockwise direction, which would not have required this segment to overcome the effects of inertia. However, as this segment was flexing under muscular control, the trunk musculature was required to contract eccentrically, consequently adding to the muscle force at the L4/L5 joint. Hence, this element was given a negative component.

\section{Determination of the moment at the L4/L5 intervertebral joint}

$$
\begin{aligned}
M_{\mathrm{j}}= & 173.15+\left(0.272\left(\cos 31.3^{\circ}\right)(32.45 \times 9.81)\right) \\
& +\left(0.133\left(\cos 31.3^{\circ}\right)(32.45 \times 2.873)\right) \\
& +\left(0.272\left(\sin 31.3^{\circ}\right)(32.45 \times 1.534)\right) \\
& +\left((0.431 \times 0.305)\left(\cos 31.3^{\circ}\right)(3420.40)\right)
\end{aligned}
$$

$$
\begin{aligned}
& +\left(0.431 \times 0.305\left(\sin 31.3^{\circ}\right)(3420.40)\right) \\
& +(3.654 \times 10.86) \\
M_{\mathrm{j}}= & 173.15+73.99+10.59+7.03+384.19 \\
& +233.59+39.68=922.22 \mathrm{Nm}
\end{aligned}
$$

Note: The horizontal $\left(a_{\mathrm{L} x}\right)$ and vertical $\left(a_{\mathrm{L} y}\right)$ components of the linear velocity were both assigned a positive direction, as the mass was being moved closer to the body and upwards. In addition to the need to overcome the resulting inertia, there was also a need to control the movement of the mass, which would have contributed to the muscle force and loading at the L4/L5 joint.

\section{Determination of the joint reaction force at the L4/L5 joint in the lumbar spine}

$$
\begin{aligned}
F_{\mathrm{M}}= & \frac{\text { Joint moment }}{\text { Distance from joint centre to muscle insertion }} \\
\therefore F_{\mathrm{M}}= & 922.22 / 0.06 \text { (estimated from research } \\
& \text { conducted by McGill (1988) and Potvin } \\
& \text { et al (1991)) } \\
\therefore F_{\mathrm{M}}= & 15370.3 \mathrm{~N}
\end{aligned}
$$

Comparison of the inverse dynamics calculation and the $4 D$ WATBAK computer software

Estimated L4/L5 compression calculated using standard Nemtonian inverse dynamics

$$
F_{\mathrm{M}}=15370.3 \mathrm{~N}
$$

Note: As it has been assumed that the trunk extensor musculature acts as one unit parallel to the vertebral column, it can be concluded that the calculated $F_{\mathrm{M}}$ value is equal to the compression force acting at the L4/L5 joint, as equal and opposite parallel forces were considered to form a Couple (Hannah and Hillier 1978).

Estimated L4/L5 compression calculated using the $4 D W A T$ $B A K$ modelling software

$$
R(\mathrm{j})_{y}=5316.5 \mathrm{~N}
$$

Comparison of the two methods of estimation

$$
\begin{aligned}
R_{\mathrm{j} \text { Comparison }}= & \frac{5316.5(4 \mathrm{D} \text { WATBAK })}{15370.3(\text { manual calculation })} \times 100 \\
R_{\mathrm{j} \text { Comparison }}= & 4 \mathrm{D} \text { WATBAK value is } 34.60 \% \text { of the } \\
& \text { manual value (i.e. } \approx 65 \% \text { lower) }
\end{aligned}
$$

Therefore, in this particular case, the estimation made by the 4D WATBAK modelling software tended to underestimate the actual load on the lumbar spine by approximately $65 \%$. 

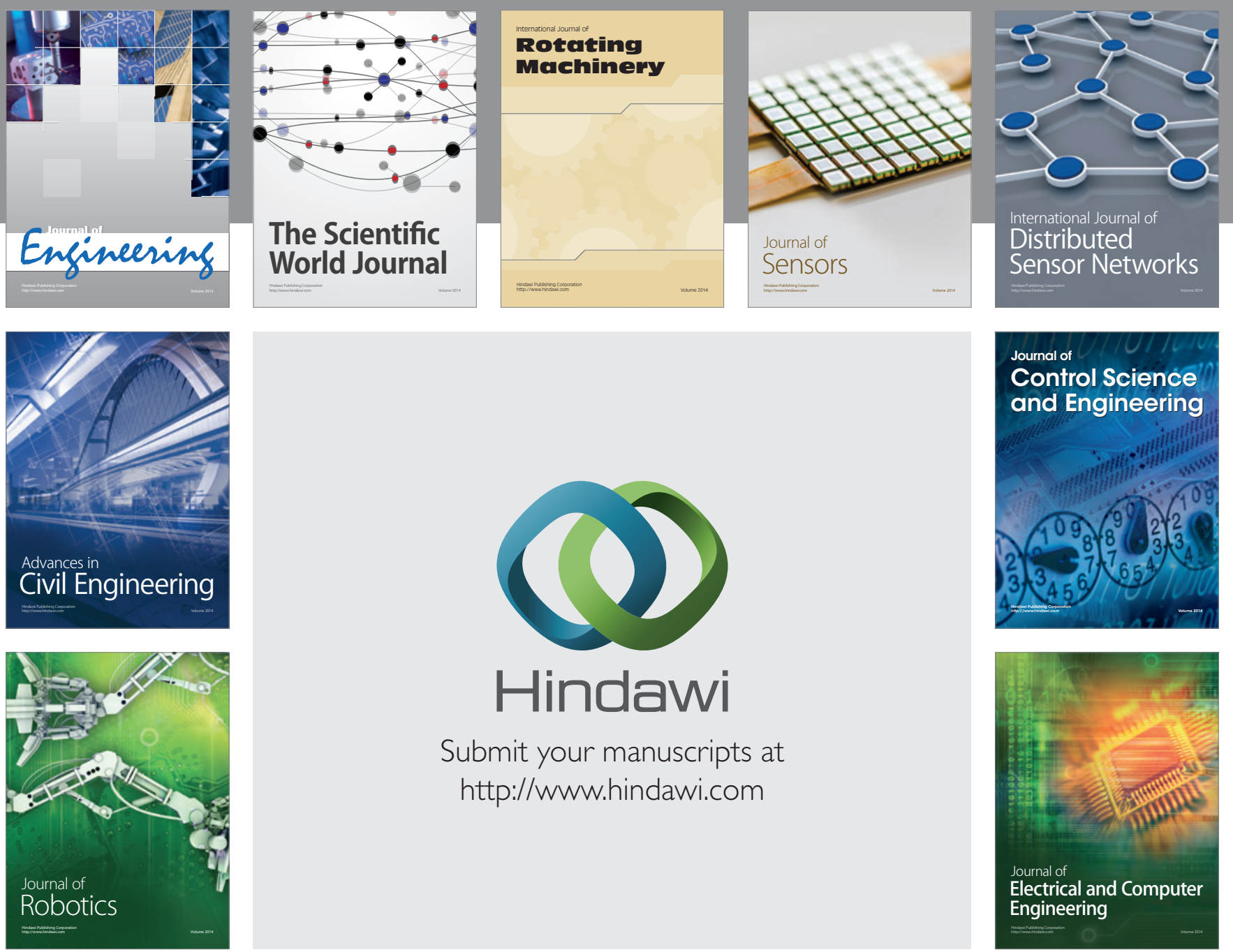

Submit your manuscripts at

http://www.hindawi.com
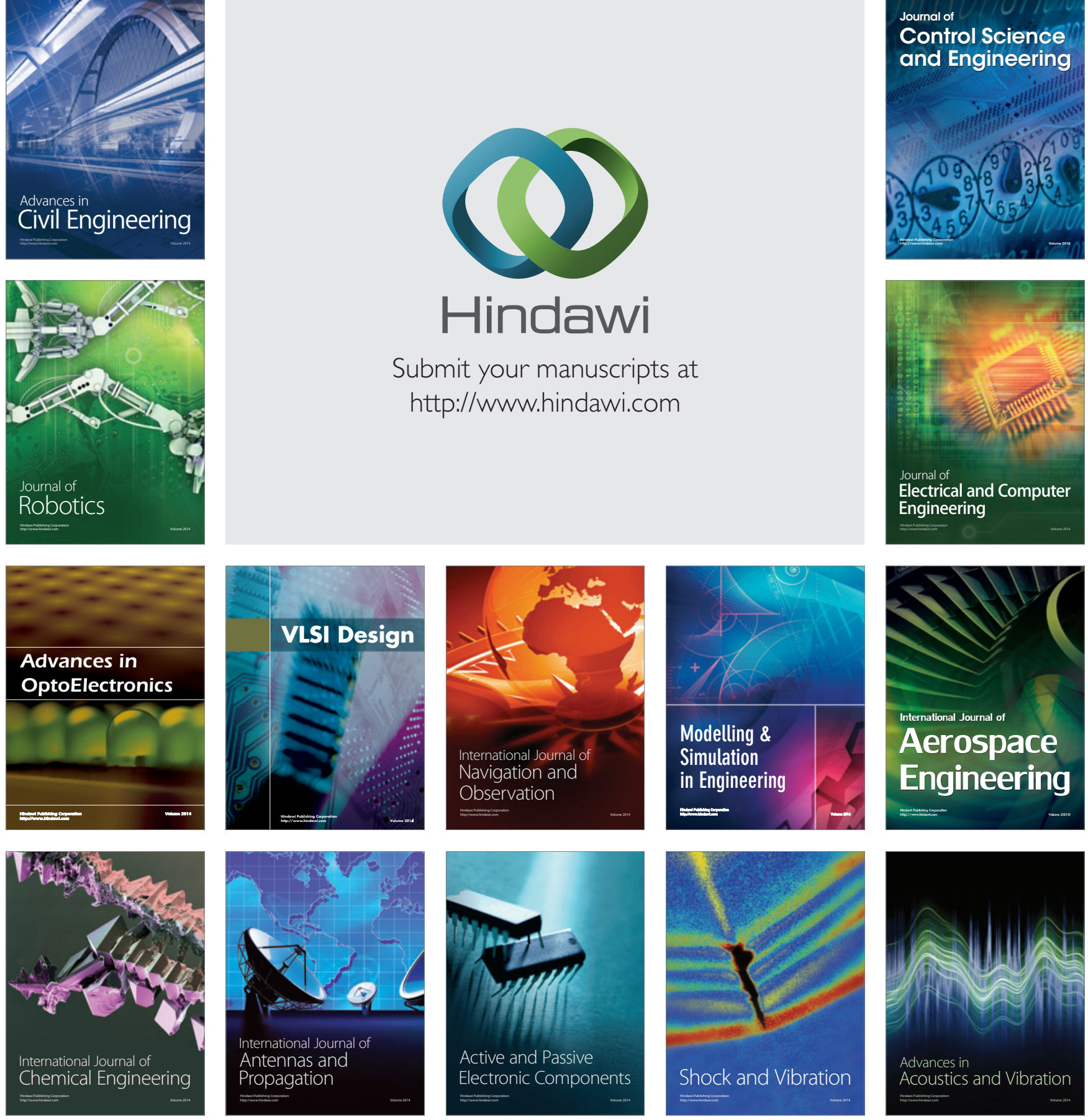